\title{
Introdução à Ciência da Computação com Computação Desplugada no Ensino Fundamental II
}

\author{
Francisco B. da Silva ${ }^{1}$, Kelinne O. Guimarães ${ }^{1}$, Moisés L. F. L. Junior ${ }^{1}$ \\ ${ }^{1}$ Departamento de Informática - Instituto Federal de Educação do Tocantins (IFTO) \\ Povoado Santa Tereza, km 07 - Araguatins - TO - Brazil \\ franciscobezerra@protonmail.com, \\ \{kelinne.guimaraes, moises.junior\} @ifto.edu.br
}

\begin{abstract}
This paper focused on the development of a methodological proposal based on the principles and fundamentals of Unplugged Computing (UC), through the methodologies of the book Computer Science Unplugged, to develop playful activities related to computer science, demonstrating that such actions can be executed without the computer use and outdoors.
\end{abstract}

Resumo. Este trabalho teve como foco o desenvolvimento de uma proposta metodológica baseada nos princípios e fundamentos da computação desplugada (CD), por meio das metodologias do livro Computer Science Unplugged, com o intuito de desenvolver atividades lúdicas relativas à ciência da computação, demonstrando que tais atividades podem ser executadas sem o uso do computador e ao ar livre.

\section{Introdução}

As tecnologias digitais de informação e comunicação (TDIC`s) são ferramentas que auxiliam no estudo e facilitam a aprendizagem de forma criativa e estimulante. Neste sentido, a introdução das TDIC's no contexto de ensino e aprendizagem é de suma importância. No entanto, em virtude da falta de recursos para aquisição e manutenção dos equipamentos de informática, o uso dessas tecnologias se torna deficitário [Sousa 2013]. A Escola Comunitária de Augustinópolis encontra-se inclusa nessa realidade, uma vez que não conta com infraestrutura tecnológica computacional para $o$ desenvolvimento de aulas na área de informática.

Frente a esse cenário nasceu a idealização deste trabalho, apresentando a computação desplugada como uma alternativa para a realização de atividades relacionadas à computação e desenvolvimento do pensamento computacional (PC), sem o uso de computadores, possibilitando um planejamento de aulas diferenciadas e de caráter lúdico. Nesse sentido, foram utilizadas atividades do livro Computer Science Unplugged para desenvolver o PC, proposto por Wing (2006), como um processo de resolução de problemas embasados nas práticas da ciência da computação, defendendo a implementação do PC desde a educação básica, pois para ele é uma habilidade de igual importância a leitura e a capacidade de resolução de cálculos matemáticos, o PC também estimula o desenvolvimento de habilidades como decomposição, abstração, generalização e raciocínio algorítmico. A importância atribuída à utilização do lúdico em aula pode ser percebida nas ideias de Verêda e Panta (2017), quando os autores afirmam que por meio das atividades lúdicas as crianças demonstram prazer em 
aprender, agir, além de gerar a autoconfiança, e também da obra de Vygotsky: uma perspectiva histórico-cultural da educação, onde defende que a aprendizagem surge a partir da interação entre os indivíduos, visando que as atividades lúdicas tenham como principal base a interação dos alunos [Rego 2013].

Nessa perspectiva, o projeto teve como resultado o desenvolvimento do Pensamento Computacional e o compartilhamento do conhecimento entre alunos, a partir das atividades desenvolvidas. Essas atividades fizeram parte de um curso introdutório à informática, no qual foi considerado o reconhecimento das principais tecnologias presentes no dia a dia dos alunos, pois constatou-se a deficiência de conhecimento na área de informática por meio da atividade diagnóstica.

A partir do trabalho de Rodrigues et al. (2018), o qual apresenta uma revisão sistemática sobre o assunto, foi possível ter acesso às literaturas que enfatizam o uso da computação desplugada, proporcionando a este projeto uma visão das mudanças que a computação desplugada pode oferece no ambiente onde é aplicada, mudança essa notada na comparação das atividades diagnóstica e final.

\section{Computação Desplugada}

A computação desplugada consiste em ensinar os fundamentos introdutórios à ciência da computação com atividades lúdicas, sem o uso de recursos computacionais, assim evitando possíveis distrações do ambiente computacional. Por se tratar de atividades simples e não ser necessário explicar detalhes técnicos dos funcionamentos dos computadores, o método pode ser desenvolvido a diversos públicos, desde crianças a adultos, não importando o seu nível de escolaridade. O destaque e que a computação desplugada não requer nenhum equipamento especializado, os alunos aprendem na prática e se divertem enquanto aprendem e cooperam entre si, as atividades podem ser utilizadas sem seguir uma ordem ou sequência, pois não dependem uma da outra para serem aplicadas.

As atividades são separadas em três partes: "Representando as Informações", "Algoritmos" e "Representando Procedimentos". Assim, em cada uma é desenvolvida um conteúdo específico da computação, a partir do uso de materiais lúdicos, como cartões, ímãs, caixas, imagens, pintar, recorte de papel, entre outros. Bell et al. (2011) sugere diversas alternativas de aplicação das atividades, dar dicas de aplicação das mesmas para alunos mais avançados, ressalta as habilidades desenvolvidas e matérias a serem utilizados.

Todas essas atividades são encontradas no livro Computer Science Unplugged, essas por sua vez estão sendo utilizadas em diferentes disciplinas como exemplo citamos a utilização da computação desplugada por Cunha e Nascimento (2018) no desenvolvimento do pensamento computacional na disciplina de robótica. A diversidade de adaptação das atividades é notada através do trabalho de Sousa e Lopes (2018), onde demonstram em seu artigo, o processo de estimular a construção do pensamento computacional e o raciocínio lógico, por com temática e simulados da Olimpíada Brasileira de Informática (OBI), com destaque da utilização da computação desplugada, quando não dispunham de laboratório de informática. 
VIII Congresso Brasileiro de Informática na Educação (CBIE 2019)

Anais do XXV Workshop de Informática na Escola (WIE 2019)

\section{Metodologia}

O presente trabalho foi desenvolvido na turma do $9^{\circ}$ ano do ensino fundamental, com 34 alunos, com idade entre 14 a 17 anos, na Escola Comunitária de Augustinópolis no estado do Tocantins, no qual não tinham disciplina de informática nem mesmo laboratório para tal. Em um primeiro momento, foi realizada uma atividade diagnóstica junto aos estudantes para mensurar o nível de conhecimentos referente à computação. A atividade contou com aplicação de questionário, contendo 12 (doze) questões abrangendo diferentes temas da computação. A partir da obtenção das respostas deste questionário, foi identificada uma deficiência em conhecimentos básicos de informática. A título de exemplo, podemos citar a dificuldade que a maioria tinha em identificar um monitor ou um computador portátil.

Tendo o diagnóstico da turma que seria assistida pelo projeto foram elaboradas atividades que pudessem contribuir para dirimir as deficiências encontradas no que tange aos conhecimentos sobre computação. No decorrer do projeto foram explorados diferentes espaços, como: a área de playground, que contava com árvores e sombra, a utilização desse ambiente possibilitou que fossem realizadas atividades ao ar livre com os estudantes. Vale destacar que a aplicação dos testes diagnósticos e teste final ocorreu em sala de aula. No sentido de avaliar a eficiência da intervenção proposta pelo projeto foi realizado um levantamento junto aos seus participantes como objetivo averiguar o nível de aprendizagem deles no que se refere à informática, por meio das atividades com a utilização da computação desplugada.

\subsection{Atividade 01 - Números Binários}

Utilizando cartões contendo pontos para representar um número, esse por sua vez é transformado em código binário como mostra na Figura 1.

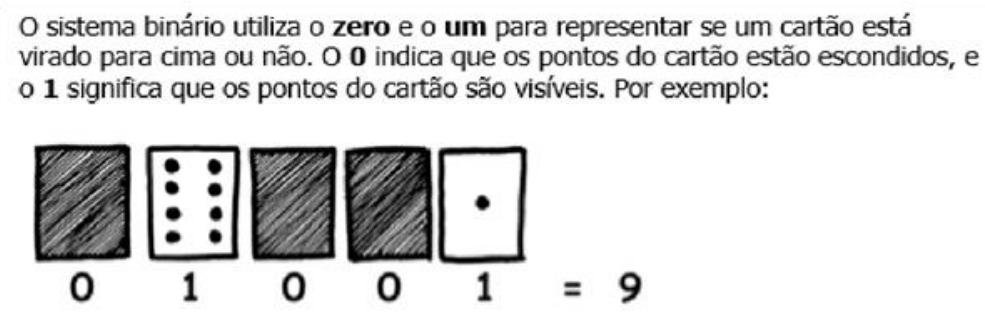

Figura 1. Atividade 01

Através da atividade 01, foi possível desenvolver o conteúdo relacionado aos números binários. Foi possível, também, com ajuda dos cartões transformar símbolos em binário, transformar os binários em números e por fim, transformar os números em letras do alfabeto e assim decifrar uma mensagem. Demonstrando aos alunos de forma simples como é processado toda informação pelo computador.

\subsection{Atividade 12 - Linguagem de Programação}

A segunda atividade aplicada enfatizou como o computador executa as tarefas propostas. A Figura 2 mostra um exemplo de aplicação da atividade 12 do livro. 
VIII Congresso Brasileiro de Informática na Educação (CBIE 2019)

Anais do XXV Workshop de Informática na Escola (WIE 2019)

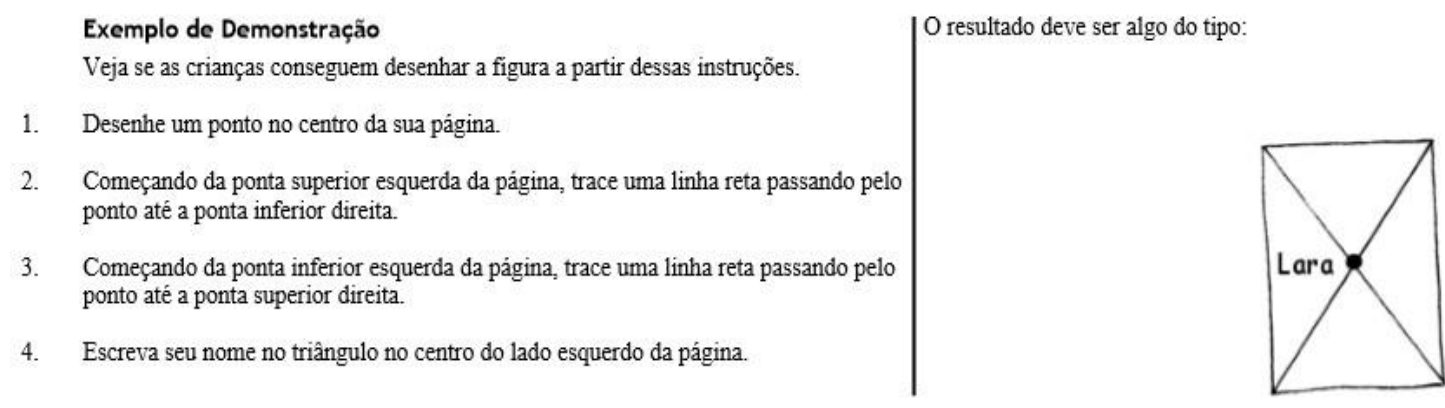

Figura 2. Atividade 12

A atividade consiste em tornar os alunos capazes de gerar comandos simples para que seu colega interprete e faça vários desenhos apenas ouvindo os comandos. Utilizando apenas folha e papel, outro aluno fica com a figura na mão sem mostra para o outro, assim como o exemplo na Figura 2. Outro exemplo de utilização é percorrer um labirinto de olhos vendados apenas executando comandos simples, assim foi possível demonstrar aos alunos todo o processo que um computador interpreta os comandos para executar uma tarefa.

\section{Resultados e Discussões}

$\mathrm{Na}$ atividade diagnóstica os estudantes responderam aos 34 (trinta e quatro) testes com 12 (doze) questões da atividade diagnóstica. Das 12 perguntas apresentadas foram obtidos $35,3 \%$ de acertos e $64,7 \%$ de erros. As alternativas que contaram com mais erros foram referentes as nomenclaturas das tecnologias e dispositivos, evidenciado o desconhecimento dos estudantes relacionados a assuntos básicos ligados à computação, com base nesta atividade foram desenvolvidas as aulas para se adequar ao nível de conhecimento dos alunos.

Após a execução das atividades previstas pelo projeto, foi realizada uma atividade que serviu como ferramenta avaliativa dos conhecimentos obtidos por parte dos alunos, durante com a realização do projeto. Esse teste foi diferente, com menos questões a serem respondidas, usando o mesmo conteúdo da atividade diagnóstica, mas com perguntas diferentes, tentando averiguar se eles aprenderam ou apenas memorizaram as respostas. Foram aplicados 44 (quarenta e quatro) testes com a soma de 220 (duzentos e vinte) questões, onde é possível identificar um maior número de acertos de questões referente ao mesmo conteúdo da atividade diagnóstica.

Durante as aulas com a utilização de técnicas da computação desplugada foi possível verificar, ainda, um maior interesse dos alunos em participarem das atividades propostas, diferente do que era notado no período de observação. Comprovando, dessa forma, que é possível deter sua atenção e despertar seu interesse com incorporação de atividades lúdicas no ambiente de ensino. Assim, com a interação dos estudantes diante do conteúdo apresentado foi possível alcançar um melhor resultado no quesito aprendizagem e desenvolver o conhecimento em computação mesmo sem o ambiente computacional.

\section{Considerações Finais}

O projeto apresentado propôs o desenvolvimento de atividades no contexto escolar com a adoção de práticas, que envolveram conceitos de computação desplugada. A partir dos 
dados obtidos foi possível concluir que a iniciativa alcançou seu objetivo, tendo em vista que os estudantes que apresentaram, inicialmente, desconhecimento de assuntos básicos relacionados à informática, após a conclusão do curso oferecido pelo projeto sabiam diferenciar CPU (Unidade Central de Processamento) de gabinete, mouse gamer de mouse comum, diferenças entre notebooks e PC (computador pessoal) de mesa, o que é uma linguagem de programação, algoritmos computacionais e não computacionais, diferenças entre os tipos de armazenamentos que o computador utiliza. Foi possível, ainda, disseminar entre outros professores informações de sites que oferece vários conteúdos que envolve jogos educativos para que eles também pudessem usar em sala de aula. Como proposta para trabalhos futuros, acreditamos que pode ser avaliado o nível do pensamento computacional a partir da utilização de metodologias adequadas para essa finalidade.

\section{Referências}

Bell, T., Witten, I. e Fellows, M. (2011) "Computer Science Unplugged. Ensinando Ciência da Computação sem o uso do computador", Tradução coordenada por Luciano Porto Barreto.

Cunha, F. e Nascimento, C. (2018) "Uma Abordagem Baseada em Robótica e Computação Desplugada para Desenvolver o Pensamento Computacional na Educação Básica". In: Brazilian Symposium on Computers in Education (SBIE). p. 1845.

De Souza, I. e De Souza, L. (2013) "O uso da tecnologia como facilitadora da aprendizagem do aluno na escola”. Revista Fórum Identidades.

De Souza, J. e Lopes, A. (2018) "Estimulando o pensamento computacional e o raciocínio lógico no ensino fundamental por meio da OBI e computação desplugada". In: Brazilian Symposium on Computers in Education (Simpósio Brasileiro de Informática na Educação-SBIE). p. 1893.

Rodrigues, S., Aranha, E. e Silva, T. (2018) "Computação Desplugada no Ensino de Programação: Uma Revisão Sistemática da Literatura”. In: Brazilian Symposium on Computers in Education (Simpósio Brasileiro de Informática na Educação-SBIE). p. 417.

Rego, T. (2013) "Vygotsky: uma perspectiva histórico-cultural da educação", Editora Vozes Limitada.

Wing, J. (2006) "Computational thinking. Communications of the ACM", v. 49, n. 3, p. $33-35$. 